\title{
Filantropia, poder público e combate à lepra $(1920-1945)^{*}$
}

\section{Philanthropy, government, and the fight against leprosy (1920-1945)}

Vicente Saul Moreira dos Santos

Doutorando do Programa de Pós-graduação em História, Política e Bens Culturais/Centro de Pesquisa e Documentação de História Contemporânea do Brasil/Fundação Getulio Vargas.

Praia de Botafogo, 190/14ㅇ andar 22250-900 - Rio de Janeiro - RJ - Brasil vsaul@uol.com.br

Recebido para publicação em abril de 2009 Aprovado para publicação emsetembro de 2010 .
SANTOS, Vicente Saul Moreira dos. Filantropia, poder público e combate à lepra (1920-1945). História, Ciências, Saúde - Manguinhos, Rio de Janeiro, v.18, supl. 1, dez. 2011 p.253-274.

\section{Resumo}

Durante a Primeira República (18891930), a criação das Sociedades de Assistência aos Lázaros e Defesa Contra a Lepra, na década de 1920, foi um marco nas relações entre as entidades assistenciais e os poderes públicos. Inicialmente aquelas entidades mantiveram autonomia decisória, mas suas diretrizes mudaram quando estabeleceram relações mais próximas com a política de combate à lepra, após a criação do Ministério da Educação e Saúde Pública, em 1930, no âmbito das reformas implementadas a partir de então, e, especialmente, durante a prolongada gestão de Gustavo Capanema à frente daquele ministério (1934-1945).

Palavras-chave: lepra; Sociedades de Assistência aos Lázaros; filantropia; ministério Gustavo Capanema (19341945); Brasil.

\section{Abstract}

The 1920s creation of Sociedades de Assistência aos Lázaros e Defesa Contra a Lepra under Brazil's First Republic (1889. 1930) represented a milestone in relations between assistance organizations and the government. Although these organizations were at first autonomous decision-makers, their guidelines changed after they established closer relations with the government, which enacted reforms in policies to fight leprosy following the 1930 creation of the Ministry of Education and Public Health, especially during the long tenure of Minister Gustavo Capanema (1934-1945).

Keywords: leprosy; Sociedades de Assistência aos Lázaros e Defesa Contra a Lepra; philanthropy; Gustavo Capanema Ministry (1934-1945); Brazil. 
Com o governo, se preciso; sem o governo, se possível; e até mesmo, contra o governo, se assim for necessário.

Alice Tibiriçá

\begin{abstract}
A Federação das Sociedades de Assistência aos Lázaros e Defesa Contra a Lepra, atendendo ao apelo do então ministro de Educação e Saúde, Dr. Gustavo Capanema, começou uma intensa campanha social, educativa e financeira em todos os Estados do Brasil, a fim de levantar renda para construir Preventórios modernos para receber crianças, ao mesmo tempo que arregimentava uma nova consciência social. Começou a Federação a coordenar pessoas de boa vontade em todos os Estados e formar, sobretudo, um corpo de doutrina que fosse capaz de trazer uma consciência contra a lepra e a favor do lázaro em todo o país, colocando-se ao lado do Governo nessa importante obra de redenção nacional.
\end{abstract}

Eunice Weaver

\title{
Primeira República e as Sociedades de Assistência aos Lázaros e Defesa Contra a Lepra
}

A proclamação da República (1889) não trouxe, a princípio, grandes mudanças no combate à lepra nem nas instituições mantidas pelas ordens religiosas filantrópicas. Até as primeiras décadas do século $\mathrm{XX}$, os estabelecimentos asilares eram destinados "a proteger a sociedade sadia do perigo representado pelos doentes; ... não implicava necessariamente na existência de serviços que se destinassem à melhoria das condições de saúde do paciente" (Monteiro, 1995, p.83). ${ }^{1}$ A construção e a manutenção dos hospitais e asilos dependiam do dinheiro arrecadado em campanhas beneficentes, mas esse tipo de atuação não se mostrava capaz de sustentar as entidades.

Durante as décadas de 1910 e 1920 houve intenso debate sobre a melhor forma de tratamento dos doentes de lepra, em grande medida devido às incertezas desse campo. Os menos severos, os humanitários, segundo definição de época, defendiam o isolamento domiciliar para os doentes que tivessem condições e o isolamento asilar somente para enfermos pobres, em instituições próximas dos centros urbanos, a serem construídas por meio de parceria entre estados, municípios e iniciativa privada. Entre os que defendiam essa postura, menciono Emilio Ribas, Eduardo Rabello e Carlos Chagas. Opostamente, os isolacionistias defendiam que todos os enfermos tinham de ser internados, não se devendo considerar a forma clínica e demais aspectos da doença nem as condições sociais do doente.

O isolamento em espaços específicos como hospitais e colônias era defendido como medida de defesa da saúde coletiva. Destacados médicos e cientistas, como Oswaldo Cruz, Arthur Neiva e Heraclídes César de Souza Araújo, defendiam a construção de instituições em ilhas, por serem de difícil acesso e assim se inibirem as fugas, mas tal proposta não pôde ser viabilizada. Outros personagens importantes, como Belisário Penna, defendiam a construção de leprosários em lugares distantes dos centros urbanos, para evitar contato 
com a população saudável. Somente após a Revolução de 1930 a construção desses estabelecimentos foi impulsionada em todo o país.

Nos primeiros anos do século XX, entidades filantrópicas laicas aliaram-se ao processo de medicalização dos hospitais. ${ }^{2}$ Elas se impuseram como canal de participação política e social das mulheres em vários outros países, não só no Brasil (Mott, 2003). Sua atuação foi pouco estudada pela historiografia brasileira, tanto no que concerne ao papel que desempenharam na formação de políticas públicas de saúde, como no tocante aos movimentos sociais protagonizados por mulheres. O papel das lideranças femininas, oriundas da 'elite', foi fundamental na implementação das políticas filantrópicas de combate à lepra.

A primeira instituição voltada para a assistência dos lázaros foi a Associação Protetora dos Morféticos, fundada em São Paulo em 27 de maio de 1917, sob a presidência de Mathilde Macedo Soares, casada com José Carlos de Macedo Soares, que fora embaixador, ministro das Relações Exteriores (1934-1936 e 1955-1956) e interventor federal em São Paulo (19451947). A entidade tinha por objetivo "auxiliar, quanto possível, e na medida que for desejada, a administrar a Santa Casa de Misericórdia de São Paulo, na assistência material e espiritual dos morféticos por ela hospitalizados" (Caiuby, 1918, p.5).

O crescimento de casos de lepra em São Paulo e as péssimas condições das antigas instituições motivaram a Associação a idealizar a construção de um leprosário-modelo, a ser entregue à Santa Casa de Misericórdia de São Paulo. ${ }^{3}$ A Associação teve apoio de dom Duarte Leopoldo e Silva, então arcebispo de São Paulo, e da Liga das Senhoras Católicas, que conseguiram arrecadar fundos para o início das obras que resultariam no leprosário Santo Ângelo (Monteiro, 1995, p.100-108). Depois de pronto, ele receberia os internos do Hospital do Guapira.

Em 1917, o arquiteto Adelardo Soares Caiuby recebeu a incumbência de elaborar o projeto, contando com "a assessoria especializada do Dr. Emilio Ribas, então diretor do Serviço Sanitário, e do Dr. Arthur Neiva, autor do Código Sanitário Nacional" (Monteiro, 1995, p.101). O plano arquitetônico, considerado modelar para instituições similares, incluía laboratórios, biblioteca, posto de saúde, necrotério, refeitório e habitações para internos e funcionários.

No começo, o governo paulista teve discreta participação no projeto, mas posteriormente o Santo Ângelo despertou maior interesse, pois não havia instituição pública para atender o crescente número de vítimas do mal de Hansen. Em dezembro de 1917, o governo de São Paulo firmou acordo com a Santa Casa, que administraria o leprosário. Conforme o acordo, as construções seguiriam as normas do Serviço Sanitário e, após seu término, a direção e a manutenção do Santo Ângelo ficariam a cargo da Santa Casa. O governo estadual daria auxílio financeiro nos cinco primeiros anos: "a organização técnica e fiscalização seriam da competência da Secretaria do Interior, órgão que compreendia o Serviço Sanitário" (Monteiro, 1995, p.102). ${ }^{4}$

Em 20 de dezembro de 1917, sete meses após a fundação da Associação Protetora dos Morféticos, o governo estadual concedeu verba para a profilaxia da lepra em São Paulo. A obra do asilo-colônia Santo Ângelo começou somente em 1919, mas devido a mudanças de governo e discordâncias quanto à localização, ficou praticamente paralisada até 1927, 
sendo concluída apenas em 1928. Enquanto isso, as associações privadas - as Sociedades de Assistência aos Lázaros - agiam no interior do estado, construindo asilos e preventórios (A endemia..., 1939).

Ao longo da década de 1920, ganhou força a ideia de que a assistência médico-social deveria reunir setores públicos e privados, com o objetivo comum de melhorar o atendimento hospitalar no país (Sanglard, 2005, p.135-136). Um dos principais líderes desse movimento foi Ataulfo de Paiva (1867-1955), que atuou na campanha pela aliança com o Estado e pela sistematização das assistências pública e privada.

A ação das entidades privadas foi fundamental para o combate à lepra. Entre suas lideranças femininas destaca-se Alice de Toledo Ribas Tibiriçá, nascida no dia 9 de janeiro de 1886, em Ouro Preto. Posteriormente foi residir em São Paulo, onde se casou com o engenheiro João Tibiriçá Neto, descendente de importante família de políticos. Durante a segunda metade da década de 1910, logo após o casamento, João Tibiriçá foi encarregado da construção de uma estrada de ferro no Maranhão e lá ficou por dois anos. Nesse período, Alice teve contato com as péssimas condições em que viviam as vítimas do mal de Hansen e, em meados da década de 1920, engajou-se nas lutas e campanhas preventivas contra a doença (Miranda, 1981).

Em fevereiro de 1926, a própria Alice Tibiriçá convocou uma reunião na casa de seu sogro, Jorge Tibiriçá, em São Paulo, ocasião em que foi criada a Sociedade de Assistência às Crianças Lázaras. Eleita sua primeira presidente, alterou o nome para Sociedade de Assistência aos Lázaros e Defesa Contra a Lepra. Os objetivos iniciais eram a propaganda da luta contra a lepra, para conseguir não apenas adeptos, como também recursos e doações para a assistência social aos doentes e suas famílias. A Sociedade inspirou a criação de instituições congêneres em todas as regiões do país. A participação de mulheres era preponderante, mas militavam também médicos, funcionários públicos e profissionais liberais.

Em 30 de abril de 1926, o Correio Paulistano noticiou, nos seguintes termos, a fundação da sociedade que foi a matriz das outras:

\begin{abstract}
A população da nossa capital assiste presentemente a um confortador movimento em prol dos lázaros e de defesa contra a lepra. Um punhado de senhoras paulistas, refletindo os nobres sentimentos que animam o coração feminino, sempre que surge uma iniciativa da mais alta filantropia, organizou a Sociedade de Assistência aos Lázaros e Defesa contra a Lepra. ... [A Sociedade,] dirigindo-se à mulher brasileira, em nome da solidariedade humana, em nome da caridade, virtude excelsa, pede o auxílio precioso de todas, o apelo material e moral para poder dar pronta solução aos seus ideais, pois urgente se torna a defesa contra a lepra, impedindo os morféticos de transitarem de cidade em cidade, propagando seu mal pelas estradas, nas camas das hospedarias, nas igrejas, nos cafés, nos cinemas, o mesmo no trabalho diário de sua subsistência ... O fim da Sociedade, conforme os seus estatutos, é socorrer os morféticos adultos, tratar das crianças lázaras, defender o país do contágio da lepra, numa campanha do Norte ao Sul. (As grandes obras..., 30 abr. 1926, p.4).
\end{abstract}

Uma das formas de angariar apoio e verba eram os eventos sociais. O mesmo periódico paulista publicou reportagens sobre os chás-dançantes ocorridos nos dias 3 a 5 de maio no Salão Egípcio do Teatro Santa Helena, com a participação de várias notabilidades da sociedade paulista. 
Enquanto isso, na capital federal, o trabalho filantrópico era desenvolvido por iniciativa quase exclusiva de uma personalidade, o engenheiro e empresário Guilherme Guinle, que atuou em diversas áreas. A filantropia apoiada por Guinle esteve muitas vezes vinculada ao projeto político e científico desenvolvido por Carlos Chagas. No caso da lepra, especificamente, Guilherme Guinle e o governo federal negociaram com representantes da Liga das Nações a criação do Centro Internacional de Leprologia, sediado no Instituto Oswaldo Cruz. No final da década de 1920, foi organizada uma comissão presidida por Guilherme Guinle e composta por Carlos Chagas, Clementino Fraga, diretor do Departamento Nacional de Saúde Pública, Eduardo Rabello, professor catedrático de dermatossifilografia na Faculdade de Medicina no Rio de Janeiro, e pelo secretário-geral Heraclídes César de Souza Araújo. O Centro foi criado em julho de 1934 e encerrou suas atividades em 1938 (Benchimol et al., 2009).

Em São Paulo, Alice Tibiriçá obteve apoio político e até uma coluna no jornal Correio Paulistano, para divulgar notícias sobre a lepra. Em 1927, com as eleições estaduais, o quadro político mudou. O candidato vitorioso Júlio Prestes começou a cercear as atividades da Sociedade, o que levou Alice Tibiriçá a proclamar: "Com o governo, se preciso; sem o governo, se possível; e até mesmo, contra o governo, se assim for necessário" (Miranda, 1981, p.11) - palavras que ecoavam o clima de insatisfação que levaria à Revolução de 1930.

Em virtude dos problemas políticos, a Sociedade optou por intensificar as campanhas de conscientização acerca da lepra e estimular a criação de outras sociedades, com objetivo de ampliar o número de adeptos e atingir maior abrangência territorial. A Sociedade de Assistência aos Lázaros priorizou, de início, cidades do interior de São Paulo como Carapicuíba e Jacareí e gradativamente se fez presente em diversas regiões do país. De certo modo, seguiu trilhas abertas pelo movimento sanitarista na década anterior no recrutamento de adesões para o combate às endemias rurais. ${ }^{5}$

Em 1928 criou-se a Sociedade de Assistência aos Lázaros e Defesa Contra a Lepra do Distrito Federal, com vários integrantes da elite carioca. Nesta e em outras Sociedades, observa-se sempre a presença de mulheres em posições de comando, notadamente as integrantes das elites locais. Artistas, políticos, empresários, funcionários públicos e outras categorias sociais engajaram-se nas campanhas de levantamento de fundos. No ano seguinte a Sociedade de Assistência aos Lázaros e Defesa Contra a Lepra do Distrito Federal iniciou a publicação de seu Boletim. Também em 1929, por ocasião do primeiro aniversário da Sociedade no Rio de Janeiro, as direções paulista e carioca encaminharam a "Mensagem das Sociedades de Assistência aos Lázaros e Defesa Contra a Lepra ao presidente da República", que era então Washington Luís, eleito em 1926. No documento, explicitavam sua visão sobre a doença e seus principais objetivos:

Das enfermidades contagiosas a lepra é a que mais tarda em se manifestar. Assim, pois, quantos imigrantes que aqui aportam vindos de países onde ela é endêmica, não na trazem porventura incubada e aqui, em clima diferente, a moléstia se vem manifestar aumentando a estatística? Sabemos todos que as terras do Brasil reclamam braços para o trabalho. Deve, pois, ser intensificada a imigração, mas, antes de tudo, havendo um aparelhamento necessário à defesa dos nossos patrícios (citado em Araújo, 1956, p.490-491). 
Havia visões diferentes sobre como combater a lepra. Por elas chocavam-se especialmente humanitários como Alice Tibiriçá, que recomendavam o isolamento domiciliar e "a construção de pequenos leprosários regionais, onde seriam internados apenas os casos excepcionais" (Monteiro, 1995, p.137), e isolacionistas, grupo majoritário nas delimitações de políticas de combate à lepra, integrado pelos principais políticos e atores sociais do projeto antileproso implantado em São Paulo e depois em todo Brasil. O regime vitorioso após a Revolução de 1930 deu grande impulso ao modelo isolacionista. A tomada de poder por Getúlio Vargas levou a grandes mudanças na política nacional de saúde, com implicações para as Sociedades e as práticas de combate à lepra. Gradualmente o governo federal assumiu funções mais amplas no combate às enfermidades, pois o Estado implementado no Brasil após 1930 tinha por postulado essencial a consolidação do poder público. Ao poder estatal caberia ser o único responsável pela gestão da saúde (Fonseca, 2007). Assim, as proposições expressas na Mensagem das sociedades ao presidente da República foram parcialmente atendidas no período varguista, como se verá adiante.

\section{Governo Vargas (1930-1945) e ação filantrópica}

As mudanças sociais e políticas ao longo da década de 1920, o choque de interesses das elites em relação à candidatura de Júlio Prestes para suceder o presidente Washington Luís, em 1929, o lançamento, pelo grupo oligárquico dissidente, da chapa de Getúlio Vargas para a Presidência do Brasil propiciaram a eclosão do movimento revolucionário que pôs fim à Primeira República e levou Vargas ao poder, iniciando-se então o seu governo provisório (1930-1934).

Naqueles mesmos anos, o Boletim da Sociedade de Assistência aos Lázaros dava notícias das sociedades filiadas, que se tinham alastrado pelas cidades de São Paulo (a sede) e Bauru (SP), Rio de Janeiro (DF), São Simão (GO), Parnaíba (PI), Juiz de Fora e Belo Horizonte (MG), Natal (RN), Salvador e São Carlos (BA). Em fevereiro de 1932 Alice Tibiriçá reuniu, na sede, os representantes dessas sociedades, com o propósito de criar a Federação das Sociedades de Assistência aos Lázaros e Defesa Contra a Lepra. Foram eleitas presidente e vice-presidente da nova entidade Alice Tibiriçá e Eunice Weaver, respectivamente. ${ }^{6}$

Eunice Weaver, nascida Eunice de Sousa Gabbi, nasceu no dia 19 de setembro de 1904, numa fazenda de café em São Manoel (SP). Em 1927, já residindo em São Paulo, casou-se com o norte-americano Charles Anderson Weaver que, logo após o casamento, foi convidado para dirigir um projeto na Universidade de Nova York, pelo qual alunos visitariam 42 países, com o objetivo de incrementar a formação acadêmica. Eunice acompanhou o grupo nessas viagens e teve a possibilidade de entrevistar Mahatma Ghandi e visitar muitos leprosários na África e na Ásia. Ao retornar aos EUA cursou Serviço Social na Universidade da Carolina do Norte. No início da década de 1930, Charles Weaver assumiu o cargo de diretor do Colégio Granbery, de cunho metodista e localizado na cidade mineira de Juiz de Fora; na mesma instituição Eunice Weaver lecionou história e geografia até 1934. Tão logo mudou-se para Juiz de Fora, ela também passou a dedicar-se à assistência social aos leprosos, tendo fundado e presidido a Sociedade de Assistência aos Lázaros e Defesa Contra a Lepra daquela cidade. A Sociedade fornecia mantimentos aos internos do leprosário Santa Isabel, 
de Belo Horizonte, e promovia campanhas para arrecadar donativos (Schumaher, Brazil, 2000).

A Federação das Sociedades de Assistência aos Lázaros e Defesa Contra a Lepra seguiu, a princípio, os ideais autônomos de ação preconizados por Alice Tibiriçá, mas gradativamente alinhou-se com o modelo de saúde federal, implementado mais sistematicamente após a posse de Gustavo Capanema no Ministério da Educação e Saúde Pública, em 1934. ${ }^{7}$ Eunice Weaver, sucessora de Tibiriçá em 1935, desempenharia papel preponderante nessa nova fase de relações mais estreitas com o governo federal.

Em 1932 Francisco Sales Gomes Júnior foi nomeado pelo governo paulista para chefiar a Inspetoria de Profilaxia de Lepra. ${ }^{8}$ Sua administração foi marcada pelo autoritarismo, sobretudo na imposição do isolamento aos portadores do bacilo de Hansen. Favorável à centralização do combate à lepra na esfera pública, Sales Gomes opôs-se à ação da Sociedade de Assistência aos Lázaros de São Paulo. A forma encontrada para cercear sua ação foi criar a Caixa Beneficente em cada colônia do estado. Comandada por um diretor e um conselho de internos indicados pelo prefeito da própria colônia, a Caixa recebia diretamente as doações e as direcionava conforme as necessidades da instituição. Na prática, a administração subordinava-se aos interesses da direção da colônia, e era vista pelo governo estadual como uma maneira de poupar gastos com ela (Monteiro, 1995, p.296-298).

Após a Revolução de 1930, havia em São Paulo, além do Santo Ângelo, o asilo-colônia Pirapitingui, o sanatório Padre Bento, o asilo-colônia de Cocais e o asilo-colônia Aimorés. Em 15 de novembro de 1933 foi fundada, por exemplo, a Caixa Beneficente do AsiloColônia Pirapitingui, localizado entre as cidades de Itu e Sorocaba e inaugurado em outubro de 1931. De acordo com seus estatutos, a Caixa era uma das associações dos internos nesse asilo-colônia e tinha por finalidade a defesa dos direitos e interesses de seus associados, que compunham a diretoria. O patrimônio era constituído não apenas por doações externas, mas também por mensalidades pagas pelos doentes, pela retribuição de serviços por eles prestados e por rendimentos auferidos com a lavoura, a criação de animais e as atividades comerciais ou industriais (Extrato dos estatutos..., 1939).

Em matérias veiculadas na grande imprensa, o governo paulista levantou suspeitas sobre a utilização das doações feitas à Sociedade de Assistência aos Lázaros, recomendando que se evitassem esses intermediários e se priorizassem as doações diretamente às Caixas Beneficentes. A campanha visava aos "falsos filantropos", como a Sociedade de Assistência aos Lázaros e Defesa Contra Lepra de São Paulo e Alice Tibiriçá, acusados de "ludibriadores e exploradores da boa fé pública e do espírito de caridade da população em geral" (Curi, 2002, p.106). Tibiriçá reagiu judicialmente contra as acusações.

Enquanto se deterioravam as relações entre as Caixas Beneficentes e as Sociedades de Assistência aos Lázaros, o presidente da Caixa Beneficente do asilo-colônia Pirapitingui endereçou carta ao ministro Gustavo Capanema, na qual solicitava seu comparecimento à inauguração de dois pavilhões-enfermarias, pois um deles receberia seu nome (Caixa Beneficente..., 1939).

Nessa conjuntura de conflito aberto instalada em São Paulo, a Federação das Sociedades de Assistência aos Lázaros organizou a Conferência Para a Uniformização da Campanha Contra a Lepra, realizada entre 24 de setembro e 2 de outubro de 1933, no Rio de Janeiro. 
O evento teve enorme repercussão e contou com participantes de quase todas as unidades federativas, com muitos médicos e membros de institutos de pesquisa. Voltaram à tona as reivindicações da mensagem ao presidente Washington Luís, sobretudo o maior envolvimento do governo federal e das administrações estaduais em ações mais efetivas de combate à lepra. Entre os assuntos debatidos figuravam:

\begin{abstract}
esterilização, proibição matrimonial, isolamento, separação compulsória dos filhos indenes, aposentadoria por lepra, expatriação interestadual de leprosos (cada um deveria ser internado somente no seu estado de origem), padronização dos leprosários, censos de lepra, criação da carteira de saúde (que atestava que seu portador não era leproso) e a instituição da obrigatoriedade de sua apresentação, publicação de uma revista nacional periódica e regular sobre leprologia, legislação específica (lei que proibisse o livre trânsito dos leprosos), infraestrutura dos leprosários, contribuição policial no recolhimento dos leprosos para internamento em leprosários, destino dos bens e imóveis dos leprosos isolados, pátrio poder dos pais leprosos (Curi, 2002, p.107-108).
\end{abstract}

Uma das consequências da Conferência Para a Uniformização da Campanha Contra a Lepra foi a participação efetiva do governo federal na construção de leprosários, permanecendo a sua administração nas esferas estaduais.

A 'defesa dos sãos' continuava a ser a principal razão que legitimava os objetivos das organizações filantrópicas engajadas na campanha antileprosa. Devido a não ter a doença caráter epidêmico, as autoridades públicas não teriam dado a devida atenção a ela. As principais medidas profiláticas recomendadas eram, então: isolamento compulsório das vítimas do mal de Hansen nos leprosários localizados nas zonas rurais; evitar a convivência de filhos sadios com os pais internos - função dos preventórios; realizar a vigilância dos familiares e dos que conviviam com os internos - papel dos dispensários. A política implementada pelos governos estaduais e pelo governo federal foi duramente criticada pelos participantes da Conferência, que defendiam a centralização das campanhas. Após a posse de Capanema no Ministério da Educação e Saúde Pública, em 1934, começou a delinear-se um plano nacional de combate à lepra apoiado neste tripé - leprosário, preventório e dispensário.

Durante a década de 1930, Alice Tibiriçá combateu a política de São Paulo, por ter não apenas imposto o regime de isolamento compulsório, como também capturado pessoas suspeitas de serem doentes de lepra (Mott, 2003). Em 1935 a sede da Federação das Sociedades de Assistência aos Lázaros e Defesa Contra a Lepra foi transferida de São Paulo para o Rio de Janeiro, em virtude dos atritos com administração estadual paulista e das vantagens decorrentes da proximidade com o governo federal. Ainda nesse ano, Alice Tibiriçá propôs que a presidência da Federação e das suas filiadas seguisse o critério rotativo. A vice-presidente Eunice Weaver assumiu então o cargo de presidente da entidade, e Tibiriçá passou a se dedicar à Sociedade de Assistência aos Lázaros e Defesa Contra a Lepra de São Paulo, a qual, após sua morte, em junho de 1950, passaria a intitular-se Instituição Alice Tibiriçá de Civismo e Sociedade. ${ }^{9}$

Entre 1932 e 1935, enquanto presidia a Federação, Tibiriçá coordenou campanhas para auxiliar financeiramente associações constituídas em São Paulo, Juiz de Fora, Bauru, Jaú, Botucatu, Belo Horizonte, Niterói e Rio de Janeiro. Seriam depois contabilizadas como 
realizações suas um pavilhão de convalescentes em Pirapitingui; um dispensário na capital de São Paulo; o prédio para a sede da Sociedade de Assistência aos Lázaros e Defesa Contra a Lepra, na mesma cidade; o pavilhão de diversões no asilo-colônia Santa Isabel, em Minas Gerais; a conclusão das obras do preventório construído pela Sociedade de Proteção aos Leprosos de Belo Horizonte; auxílio à Sociedade Fluminense e à do Rio de Janeiro; e a construção do pavilhão de diversões no Hospital-Colônia de Curupaiti, em Jacarepaguá, Rio de Janeiro (Sociedades..., 1960, p.9).

Conforme mencionado, após a revolução de outubro de 1930 a Federação passou por uma série de mudanças e perdeu o caráter autônomo para alinhar-se ao modelo varguista de saúde. O posicionamento de Alice Tibiriçá deve ser destacado como contraponto à gestão de sua sucessora na Federação, pois Eunice Weaver buscou sempre o apoio estatal e usou seu capital simbólico nas negociações para viabilizar o projeto da entidade. As atividades filantrópico-assistencialistas desenvolvidas pela Federação das Sociedades de Assistência aos Lázaros e Defesa Contra a Lepra durante o período em que foi presidente devem ser compreendidas como parte constituinte da política governamental de combate à enfermidade. O trabalho da Federação foi considerado componente fundamental do Plano de Combate à Lepra, implementado por Capanema durante a Era Vargas, e em muitos momentos teve abrangência maior do que a do poder federal, pois, como bem observou Sanglard (2005, p.140), "a iniciativa privada conseguia realizar obras muito mais rapidamente do que o Estado". A Federação e suas filiadas foram reconhecidas como de utilidade pública pelo decreto 1.473, de 8 de março de 1937. O ato pode ser compreendido como apoio ostensivo do Ministério da Educação e Saúde à política preventorial adotada pela Federação.

Durante a gestão de Eunice Weaver, a Federação passou a dar assistência direta apenas aos filhos sãos dos internos nas colônias, cabendo aos preventórios acomodar crianças e adolescentes até os vinte anos (Documentos..., 1935). As vítimas do mal de Hansen e as respectivas famílias passaram para a jurisdição do governo federal. A ação filantrópica da Federação era agora movida pela preocupação de exercer controle social sobre os descendentes dos leprosos - uma preocupação mascarada em um discurso sobre a melhoria das condições de vida. As relações pessoais de Eunice Weaver com os integrantes do governo de Getúlio Vargas, especialmente com o ministro Gustavo Capanema, redundaram em considerável apoio político e financeiro para a obra preventorial. Ressalte-se que, em 1935, existiam, no Brasil, dois preventórios com cerca de duzentas internas; 14 anos depois, aumentou para 26 o número de instituições, com mais de 3.500 crianças internadas (Weaver, 1949).

Paralelamente à centralização política levada a efeito pelo governo federal, a nova diretoria da Federação também centralizava as atividades filantrópicas de combate à lepra na sua presidência, estabelecida na capital federal. A aliança entre a Federação e o Ministério da Educação e Saúde garantiu o fomento das atividades assistenciais, especialmente a construção de preventórios, mas o estreitamento do vínculo com o projeto nacional não deixou mais espaço para questionamentos políticos, como nos tempos de Alice Tibiriçá. Ao analisar os meios de combater a lepra, em 1937, Capanema destacava que a verba dada pelo governo federal para construção de preventórios ficaria sob a responsabilidade da Federação, que, por meio de suas associações filiadas, estava presente em todas as regiões do país (Capanema, 1937). 
A relação entre a presidência da Federação e as filiadas se modificou quando os recursos passaram a ser enviados para sua sede, no Rio de Janeiro, e de lá eram encaminhados conforme as necessidades de cada sociedade. Essa centralização dos recursos garantiu à Federação uma "posição intermediária nesta hierarquia", pois permaneceria "acima das Sociedades de Assistência aos Lázaros e Defesa Contra a Lepra locais espalhadas pelo país, as quais dominava, e abaixo do Ministério da Educação e Saúde (MES), ao qual era subordinada" (Curi, 2002, p.118).

Durante a Era Vargas e nos anos seguintes, a Federação colaborou com as reformas dos leprosários e, ao mesmo tempo, procurou aumentar o número de entidades filiadas, potencializando o recrutamento de adeptos e doações que auxiliariam na construção de preventórios em todo o país. Curi (2002, p.120) explica como eram fundadas as novas entidades:

A presidente da Federação das Sociedades de Assistência aos Lázaros e Defesa contra a Lepra realizava uma visita à cidade escolhida, durante a qual apresentava algumas palestras e encontros, nos quais se fazia o apelo pedindo o auxílio para a "salvação da raça". Algumas pessoas eram quase sempre procuradas por serem consideradas de utilidade estratégica para o sucesso da causa. Eram elas: a primeira-dama municipal, médicos, autoridades municipais, advogados, delegados, jornalistas, representantes de toda imprensa local, vereadores entre outros.

A propaganda das atividades da Federação era feita no Boletim ou em publicações editadas com esse intuito, a exemplo do folheto "Uma campanha de solidariedade humana e interesse nacional" (Federação..., 1943), que continha a folha anexa:

\section{APELO AO LEITOR}

Todos estão dando a sua cooperação! Todos estão participando desse gigantesco combate à lepra no Brasil. É indispensável, amigo leitor, o seu apoio, o seu incentivo e também a sua oferta - por pequena que seja!

Em qualquer lugar do Brasil que o leitor esteja, hoje, há uma Sociedade de Assistência aos Lázaros pedindo o seu auxílio! Há um preventório que precisa da sua ajuda, AGORA!

Como fazê-lo?

a) Peça sua inscrição no corpo social da nossa Sociedade.

b) Envie seu auxílio, em dinheiro, roupas, objetos de uso pessoal, etc., para a Sociedade de Assistência aos Lázaros, que serão rigorosamente aplicados e utilizados em beneficio dos lázaros e dos seus filhos sadios.

O discurso usual para legitimar a ação preventorial, isto é, a separação dos filhos de leprosos do seio de suas famílias, era que ela beneficiaria a criança ao evitar o convívio com a doença e, dessa forma, reduzir a possibilidade de contágio. Para Weaver (1949), era enorme a dificuldade de manter essas crianças, por parte dos outros membros da família. Ficavam elas desamparadas, pelo receio do risco de contágio. Os preventórios constituíam, assim, uma solução para esses "órfãos de pais vivos". Contudo, a realidade dos internos era muito diferente e distanciava-se desse discurso, pois o "estigma congênito" os acompanhava "por toda a vida, diminuindo suas possibilidades de vida social, e obrigando-os a esconder sua ascendência, se quisessem competir em igualdade de condições quando da procura de um 
emprego ou no estabelecimento de relações sociais" (Monteiro, 1995, p.337). Nos preventórios, os vínculos afetivos com a família eram desestimulados, dificultando-se visitas e troca de correspondência.

As interlocuções da Federação com o governo federal eram estreitas e frequentes. Em setembro de 1938, a vice-presidente da entidade, América Xavier da Silveira ${ }^{10}$, entregou ao presidente da República um memorial sobre as atividades da instituição, no qual realçava o interesse de Vargas em ser notificado das ações que implementava em parceria com as Sociedades de Assistência aos Lázaros. Como vimos, uma das principais era a construção de preventórios, mas para isso eram necessários vultosos recursos, que alguns governos estaduais não possuíam. $\mathrm{O}$ documento defendia a necessidade de maior e mais frequente verba federal para a manutenção da política preventorial, apresentada como vertente da política varguista de saúde pública. O auxílio da União era urgente, pois alguns dos estados inadimplentes tinham muitos casos de lepra espalhados por vastos territórios (Memorial..., 1938).

Tal posicionamento é bem ilustrado por episódio ocorrido entre 1938 e 1940. Alguns funcionários do Departamento Nacional de Saúde enviaram telegramas ao ministro Capanema informando-o da construção, pelo governo do Espírito Santo, de um preventório para cinquenta crianças em Vitória. Entre os pontos destacados na correspondência constavam o pedido de urgência da verba federal e a liberação da concorrência pública para o empreendimento. O próprio ministro aconselhou o presidente Vargas a conceder a dispensa, e logo depois foi publicada no Diário Oficial a liberação dos recursos (Documentos..., 1938-1940). Em meados de 1940, Capanema enviou telegrama ao interventor do Espírito Santo entre 1930 e 1943, João Punaro Bley, em que requisitava informações sobre as despesas com a instalação do preventório de Vitória, realizadas com verbas da União. O ministro indagava se a instituição estava sob a administração estadual, pois, neste caso, ela devia ser transferida para a Federação das Sociedades de Assistência aos Lázaros, que coordenava todos os serviços de proteção aos filhos de leprosos. O telegrama com a resposta do governante estadual destacava que o preventório Gustavo Capanema, construído com recursos enviados ao estado pelo Ministério da Educação e Saúde, estava sob os cuidados da Sociedade Espiritossantense de Proteção aos Lázaros, filiada à Federação de Assistência aos Lázaros (Documentos..., 1938-1940).

Em junho de 1939 Gustavo Capanema presidiu uma sessão da Sociedade de Assistência aos Lázaros e Defesa Contra a Lepra do Distrito Federal. Na ocasião foi apresentado relatório sobre o patrimônio da Sociedade e teve lugar a troca da presidência dessa instituição, que passou de Marina Bandeira de Oliveira para América Xavier da Silveira, até então vicepresidente da Federação (Documentos..., 1939-1940). No mesmo ano, a presidente encaminhou ao Ministério relatório com informações sobre os preventórios construídos com a ajuda das "campanhas de solidariedade", promovidas pela entidade em benefício de suas filiadas. Informava os preventórios que já estavam em funcionamento, o número ou a previsão de internos, o andamento das obras e onde havia ainda necessidade de construir novas unidades (Documentos..., 1939-1940).

Em novembro de 1939, a presidência da Federação, no Rio de Janeiro, convocou a Conferência Nacional de Assistência Social aos Lázaros, sob auspícios do Ministério da 
Educação e Saúde. Funcionavam então três preventórios, 15 estavam em construção, e a Federação contava com 75 sociedades filiadas. Durante o evento, destacou-se a importância de se criar, no âmbito do Ministério, um serviço nacional para a lepra semelhante aos que existiam para outras doenças. A proposta foi colocada em prática, e em 1941 surgiu o Serviço Nacional de Lepra. Outra reivindicação da Conferência foi a troca do nome 'preventório' por 'educandário', com o objetivo de livrar do estigma as crianças neles internadas. Mesmo assim, meninos e meninas permaneceriam identificados como internos dos preventórios e, como indicam estudos como o de Monteiro (1995, p.375-379), continuariam a sofrer as consequências de serem descendentes de leprosos.

Dez dias após o encerramento da Conferência, Eunice Weaver comunicou ao presidente Vargas que, por decisão unânime, ficara estabelecido que apenas as Sociedades de Assistência aos Lázaros poderiam arrecadar donativos públicos para as vítimas do mal de Hansen e suas famílias. Por terem a adequada personalidade jurídica, deveriam ser autorizadas a desempenhar suas funções pelos órgãos competentes dos estados e do Distrito Federal e pelo "Serviço Oficial de Lepra" (Weaver, 1939).

Em fevereiro de 1940 a Sociedade Amazonense de Assistência aos Lázaros e Defesa Contra a Lepra comunicou a Capanema que o educandário de Manaus levaria seu nome, em retribuição ao apoio que vinha dando às ações contra a doença naquele estado (Documentos..., 1940). No mesmo ano, elaborou-se o "Regulamento dos preventórios para filhos sadios de lázaros instalados no Brasil", aprovado em 27 de janeiro de 1941 pelo Departamento Nacional de Saúde. A redação ficou a cargo da Comissão Técnica Organizadora do Regulamento, composta por Ernani Agrícola ${ }^{11}$, Heraclídes César Souza Araújo, Manoel Ferreira, Nelson Souza Campos e Eunice Weaver. ${ }^{12}$ Além de definir os objetivos daquelas instituições - manter e educar os filhos e dependentes das vítimas do mal de Hansen -, o regimento estabelecia como seriam dirigidos e administrados os preventórios. Eles permaneciam vinculados às Sociedades e à Federação das Sociedades de Assistência aos Lázaros, sabendo-se que os membros que trabalhassem nos preventórios não poderiam ser remunerados. Os preventórios contariam com um médico-clínico pediatra, encarregado de examinar semanalmente os internos, "orientando o seu desenvolvimento físico dentro das normas eugênicas e registrando o respectivo aproveitamento individual"; e um médico dermatoleprólogo, que manteria sob vigilância os internos, "levando em conta o grau de contagiosidade do foco de onde provieram, a natureza e o tempo de convivência". Caberia a esse médico, também, examinar cada criança mensalmente, nos três primeiros anos de internamento, e efetuar provas de laboratório necessárias a esse fim (Regulamento..., 1940). Nesses locais haveria ainda um dentista, um enfermeiro nutricionista, um educador e um agrônomo (Regulamento..., 1940). Foi regulamentado também o orçamento interno, além do ensino a ser ministrado aos internos, que consistiria em "jardim da infância; primário, de acordo com o programa oficial; escola doméstica em todas as suas múltiplas atividades; pequena lavoura e trabalho de campo; artes e ofícios" (Regulamento..., 1940).

O regulamento estabelecia os critérios de admissão aos preventórios, que se destinavam preferencialmente às crianças que, nascidas nos leprosários, deveriam ser de lá transferidas para o berçário daquelas instituições. A eles seriam encaminhadas também as crianças que se achassem "em focos que ofereçam maior perigo de contágio; os mais necessitados por 
falta absoluta de recursos ou assistência; os de mais tenra idade". As idades-limite para admissão seriam 15 anos para meninos e 18 anos para meninas. Os motivos para sair dos preventórios eram morte, desenvolvimento da lepra, ultrapassagem dos limites etários (18 anos para homens e 21 anos para mulheres), obtenção de trabalho vantajoso ou casamento e, por fim, comportamento indisciplinar. Neste caso, a criança era expulsa desde que tivesse mais de 15 anos e tivesse parentes ou "pessoas estranhas reconhecidamente sadias e de idoneidade moral", capazes de manter e educar a criança transgressora, a qual permaneceria sob a vigilância das autoridades sanitárias competentes. As normas eram rigorosas para os que não se comportassem devidamente: além da expulsão, estavam sujeitos à admoestação, repreensão e supressão de passeios, festas e jogos (Regulamento..., 1940). Como pode ser notado, o regulamento revela uma orientação pedagógica com forte tendência autoritária.

Fugas e rebeliões eram constantes entre os internos (Monteiro, 1995, p.370-375). Caso não seguissem as regras, recebiam punições diversas, como revela o depoimento de uma exinterna, tomado por Monteiro (p.370):

Não era só por fuga. Tinham duas meninas, coitadas, que faziam xixi na cama. Nunca me esqueço disso. Eles raspavam a cabeça, punham camisolão... Uma amiga, uma vez ela estava conversando com um menino, ela levou um tapa no rosto, só porque estava conversando. Teve uma outra que eles achavam que estava namorando, eles rasparam a cabeça dela, botaram camisolão e ficou sem sair, enquanto o cabelo não crescesse não podia sair. Porque nós íamos à matinê.

O decreto-lei 4.827. de 12 de outubro de 1942, reconheceu a Federação como instituição assistencial de caráter particular integrada à campanha contra a lepra do governo federal. A Federação e suas filiadas - cujas diretorias exerciam suas atividades voluntariamente tornavam-se, assim, de direito, as únicas entidades autorizadas a promover a assistência social em beneficio dos lázaros e de seus dependentes, em todo território brasileiro. Em 1943 a Federação contabilizava 23 preventórios em funcionamento, com cerca de dois mil "filhos de lázaros" (Federação..., 1943).

Assim como Guilherme Guinle desempenhou importante papel na implementação do Centro Internacional de Leprologia durante o governo Vargas, outras personalidades engajaram-se em ações filantrópicas em prol da saúde, ainda que de forma menos consistente e constante do que aquele empresário.

Entre maio de 1943 e agosto de 1945 transcorreu a campanha organizada por Béatrix Reynal, pseudônimo da poetisa francesa Marcelle Jaulent dos Reis, casada com o pintor mineiro José Maria dos Reis Júnior. ${ }^{13}$ Ela atuou em diversas causas sociais e foi compositora musical, tendo feito letras para melodias de Francisco Mignone. No campo da política, colaborou, ainda que a distância, com a Resistência francesa durante a Segunda Guerra Mundial. Foi mecenas do pintor e gravurista Oswaldo Goeldi (1895-1961), que lhe deixou toda a sua obra, a qual foi doada, em grande parte, para a Biblioteca Nacional após a morte do artista. Béatrix Reynal manteve relações de amizade com intelectuais brasileiros e estrangeiros, entre eles o poeta francês Blaise Cendrars, e a elas recorreu em beneficio de entidades e enfermos auxiliados pela Sociedade do Distrito Federal de Assistência aos Lázaros, também conhecida como Sociedade de Lázaros Marina Dias. 
Os doadores recrutados por influência de Reynal e os respectivos valores revelam o grande envolvimento de parte da sociedade carioca nessa causa. Na lista encontram-se empresas, pessoas de destaque na vida política e cultural do Brasil - Guilherme Guinle entre elas - e, curiosamente, um órgão público, o Departamento Nacional do Café. Entre as primeiras, destacam-se a Companhia de Cigarros Souza Cruz, o Moinho Inglês e instituições financeiras como Murray, Simonsen \& Co., Banco Moreira Salles, Banco Brasileiro do Comércio e Monteiro, Aranha \& Cia. Limitada. Também figuram a Livraria Kosmos e a Livraria Geral Franco-brasileira, assim como as firmas comerciais Casa Krause, Casa Sloper, Casa Suisso-Brasileira e Confeitaria Pirajá. Do ramo farmacêutico, colaboraram Produtos Químicos Sandoz Ltda., Produtos Químicos Ciba e Produtos Roche (químicos e farmacêuticos S.A.). As instituições de ensino Liceu Francês (alunos) e Colégio Batista (corpo docente e discente), o periódico Correio do Norte e o Cassino Balneário da Urca S.A. também assinam a lista de colaboradores. Entre as personalidades, além da própria Béatrix Reynal e de Guinle, encontram-se artistas como Lasar Segall, Oswaldo Goeldi e Rachel de Queiroz e membros da sociedade como Viriato Dornelles Vargas (irmão de Getúlio Vargas), o jornalista e político Carlos Lacerda, o general Eurico Gaspar Dutra, então ministro da Guerra (5 ago. 1936-3 ago. 1945), Joaquim Pedro Salgado Filho, então ministro da Aeronáutica (20 jan. 1941-30 out. 1945). Muitas dessas pessoas e entidades fizeram mais de uma doação para a campanha.

O valores arrecadados foram repassados à Sociedade do Distrito Federal de Assistência aos Lázaros, recebendo Béatrix Reynal um comprovante de doação assinado por um membro da diretoria. ${ }^{14}$ Na reunião anual de 1944 dos conselhos Deliberativos, Fiscal e Técnico da Sociedade do Distrito Federal de Assistência aos Lázaros, ressaltou-se a importância da campanha organizada por Reynal, para a qual foi proposta uma homenagem em nome da Sociedade (Campanha..., 1946), publicada no diário carioca O Jornal (Sociedade do Distrito Federal..., 14 abr. 1945).

Na segunda metade da década de 1940, essa e outras campanhas de solidariedade angariaram o total de Cr\$24.254.403,30, usados na construção e instalação de preventórios em todas as unidades federativas. Desse montante, a campanha de Reynal arrecadou Cr\$6.000,00. O Ministério Capanema contribuía com mais de Cr\$1.000.000,00 para as ações da Federação. Após o fim da Era Vargas, essa entidade aumentou as campanhas de solidariedade, com o fim de manter seu projeto assistencial. Em 1948 foram captados Cr\$8.122.301,30, por meio de festas e doações dos sócios das Sociedades (Weaver, 1949, p.6). Cabe ressaltar que, no governo do presidente Dutra (1946-1951), os recursos para a Federação diminuíram consideravelmente, logo, os donativos tornaram-se muito importantes para a manutenção do projeto preventorial (Weaver, 1949).

Em diversos momentos, Eunice Weaver, como presidente da Federação das Sociedades de Assistência aos Lázaros e Defesa Contra a Lepra, foi solicitada a mediar problemas entre as administrações estaduais e as direções dos preventórios (Documentos..., 1935). Isso evidencia a liderança que exercia e o reconhecimento não apenas das companheiras das diversas Associações, como também das elites políticas locais.

Na mesma conjuntura a Federação começou a atuar como instrumento da política externa. O governo Vargas priorizou acordos internacionais favoráveis ao café, principal 
produto da economia brasileira. Destaca Moura (1993, p.179) que na década de 1930 a política externa brasileira "pode ser descrita como uma política de equidistância pragmática entre duas potências [EUA e Alemanha] tanto em questões comerciais, como políticas e militares". Durante a Segunda Guerra Mundial, o país manteve-se neutro por considerável tempo, fazendo alianças econômicas com os dois países. Contudo, durante a gestão de Oswaldo Aranha no Ministério das Relações Exteriores (1938-1944), buscou-se fortalecer a união pan-americana por meio da aproximação do Brasil com países da América Latina e de acordos com o governo norte-americano (Abreu et al., 2001, grifos do original).

A política de combate à lepra e a mobilização da filantropia por parte do Estado, durante a gestão ministerial de Capanema, foram utilizados como propaganda da saúde pública brasileira. Em março de 1939, Alzira Vargas encaminhou a Gustavo Capanema pedido do governo cubano de todas as publicações do ministério sobre a lepra, o que evidencia a notoriedade da política adotada no Brasil (Vargas, 1939). Em setembro de 1943, Eunice Weaver enviou carta ao ministro em que agradecia a forma como fora apresentada ao ministro da Saúde do Paraguai, às vésperas da visita que faria a Assunção, para divulgar a política médica e assistencial do ministério varguista (Weaver, 1946). As ações externas de Eunice Weaver como presidente da Federação das Sociedades de Assistência aos Lázaros e Defesa Contra a Lepra prosseguiram após o governo Vargas, mas tendo sempre a gestão de Capanema como modelo a ser exportado a outros países do continente. ${ }^{15}$

No caso colombiano, a filantropia teve apoio do empresário Guillermo Greiffenstein, que, após comparecer ao Congresso de Havana, em 1948, fundou em Medellín a Liga Nacional de Ayuda a los Leprosos. A entidade publicou uma revista de divulgação, uma cartilha informativa, beneficiou centenas de enfermos com tratamento gratuito, realizou melhorias nos leprosários e nos preventórios para meninos sadios (Torres, 2002, p.351352). As mulheres também foram convocadas, pela imprensa médica, para organizar instituições de caridade para crianças no bojo de campanhas antileprosas. Sociedades de caridade e preventórios amparavam órfãos, e as mulheres que militavam nas sociedades filantrópicas passaram a encarar a separação dos filhos de seus pais enfermos como uma missão. Na década de 1940, em Bogotá, a Sociedad de Prevención Infantil, comandada por Elvira Lleras Restrepo, cuidava de um preventório feminino. Essa política seguia o modelo implantado no Brasil e, em seguida, na Argentina, sendo difundida a "imagen de la gran heroína de la filantropía, la brasileña Eunice Weaver, esposa de un profesor norteamericano, quien recorría el mundo pronunciando discursos emotivos" (p.351).

Entre agosto e setembro de 1946, Weaver realizou uma viagem por países da América, para divulgar, por meio da exibição de filmes sobre leprosários e preventórios, a política de combate à lepra adotada no Brasil (Weaver, 1946). De Nova Orleans, enviou a Capanema longo telegrama sobre as impressões da viagem a Cuba, em que destacava o êxito do governo cubano na educação e na saúde. Em Havana, Weaver proferiu palestras e fundou duas Sociedades de Assistência aos Lázaros, a pedido do ministro cubano de Saúde e Assistência. As autoridades daquele país prometeram um preventório para o ano seguinte. Em outras cartas a Capanema, Eunice Weaver narrou visitas feitas ao México, Guatemala, Costa Rica e Equador. Em todos eles, proferiu palestras ressaltando a atuação do governo Vargas no combate à lepra (Weaver, 1946). 
Ao final do Estado Novo, num momento em que, no continente americano, se acirravam a oposição aos regimes autoritários, as pressões pela redemocratização e a ampliação dos canais de debate social, aconteceu na capital brasileira a Segunda Conferência Nacional de Assistência Social aos Lázaros, em julho de 1945. Deveu-se a pedido feito pelo ministro Capanema diretamente à presidência da Federação. Patrocinada por Getúlio Vargas, que compareceu à cerimônia de encerramento, o evento teve como presidente de honra o próprio ministro da Educação e Saúde, que proferiu um discurso na sessão inaugural. A comissão organizadora foi comandada por Eunice Weaver e Ernani Agrícola. A Segunda Conferência superou a primeira, ocorrida em 1939: contou com mais de cem entidades filiadas, além de médicos e funcionários do Serviço Nacional de Lepra e outros serviços de saúde pública. Dela participaram também delegações internacionais (Conferência..., 1946).

Ernani Agrícola, chefe do Serviço Nacional de Lepra, destacou a importância do evento, dos temas debatidos e o papel da Federação no combate à lepra, ressaltando que a subvenção anual do ministério para a área preventorial ascendia a Cr\$1.000.000,00 (Conferência..., 1946, p.30).

A centralização na presidência da Federação e a estreita aliança com o ministério são evidenciadas nos regulamentos dessa Segunda Conferência, pois foram considerados membros dela os delegados das Sociedades de Assistência aos Lázaros, filiadas à Federação; os representantes oficiais do governo da União, dos estados, do Distrito Federal, dos territórios e dos municípios. Os temas debatidos foram: "I - Assistência Social aos filhos sadios dos doentes de lepra; encaminhamento do egresso dos preventórios; II Funcionamento e manutenção dos preventórios; III - Trabalho educacional nos preventórios: sua orientação e execução; IV - Reajustamento social das famílias dos doentes de lepra; e V - Assistência social aos doentes de lepra" (Conferência..., 1946, p.14-15).

Dentre as conclusões relativas ao primeiro tema, destaca-se a orientação de que a assistência social ao filho sadio do lázaro deveria ser responsabilidade dos familiares; na impossibilidade, seria forçosamente encaminhado para os preventórios (Conferência..., 1946, p.373).

Quanto ao segundo tema, a presidência da Sociedade de Assistência aos Lázaros era a responsável por definir a orientação geral dos preventórios por ela administrados. As direções dessas instituições deveriam estabelecer acordos com os Serviços Estaduais de Profilaxia da Lepra para obter leprólogos-dermatologistas, responsáveis pela vigilância sanitária dos internos. Sobre a relação entre filantropia e serviços médicos, ficou estabelecido que o administrador de cada preventório não deveria, de modo algum, entrar em conflito com "as recomendações de ordem médica e profilática" (Conferência..., 1946, p.373). Os recursos para manutenção das atividades preventoriais provinham de contribuições particulares e dos governos federal, estadual e municipal. Caberia à sociedade solicitar aos poderes públicos o aparelhamento tecnoeducativo e o pessoal necessário. Os internos trabalhavam com a finalidade de aprendizagem e tinham "liberdade de escolha moral e espiritual", desde que observassem "os princípios da crença em Deus" (p.374).

O terceiro tema versava sobre orientação educacional. Além do ensino formal, os internos deveriam ter acesso a esportes, áreas de lazer e poderiam formar grupos de escoteiros e bandeirantes. As administrações públicas encaminhariam professores especializados para 
ensinar atividades industriais e agrícolas. Em acordo com determinações da Conferência Nacional de Assistência, de 193916, reafirmou-se que "para eliminar preconceitos sociais contra a descendência dos leprosos, os estabelecimentos destinados a seus filhos sadios deverão ter, de preferência, a denominação de 'educandário'" (Conferência..., 1946, p.374).

A inserção dos internos na sociedade era o quarto tema. A orientação aprovada dizia:

para a campanha do reajustamento social, necessário se torna firmar no espírito público, a fim de evitar injustificado receio em face dos dependentes dos lázaros: a) que os mesmos não constituem perigo para a sociedade quando sob perfeita vigilância sanitária; b) que a lepra só se transmite após contato real, íntimo e prolongado com doente contagiante; c) que a doença é suscetível de cura e não é hereditária; d) que os filhos dos lázaros, quando retirados do meio infectante, ao nascer, ficam isentos do mal (Conferência..., 1946, p.375).

Os trabalhos realizados pelos internos em leprosários e preventórios deveriam ser remunerados, e as famílias receberiam auxílio financeiro para facilitar seu reajustamento social. América Xavier da Silveira, presidente da comissão formada para tratar desse tema, destacou que a Sociedade do Distrito Federal de Assistência aos Lázaros, em 1945, doava a cada família pensão mensal de Cr\$1.000,00 (Conferência..., 1946, p.290), além de receber alimentos, roupas e utensílios coletados por campanhas de doação.

O grupo de trabalho que tratou da assistência social aos lázaros como dever social formulou propostas que seriam enviadas aos órgãos competentes: isenção de impostos e taxas federais, estaduais e municipais para propriedades de lázaros; reconhecimento, por parte da União, das organizações estaduais de assistência judiciária e extrajudiciária aos doentes de lepra e seus dependentes; isenção de impostos para instituições beneficentes, doentes e suas famílias; concessão, pelos Institutos e Caixas de Aposentadoria e Pensões, de salário integral para os lázaros; revisão da lei de registro civil, a fim de não constarem os leprosários nas certidões de nascimento, casamento e óbitos, mas sim no distrito de paz em que ocorreram; e, por último, que a lepra não fosse indicada como causa mortis nos atestados de óbito (Conferência..., 1946, p.375).

Ao analisar os anais dessa Conferência, percebe-se a ratificação e ampliação do conteúdo do Regulamento dos Preventórios, assim como o endosso das conclusões da Primeira Conferência, de 1939. A de 1945 foi um evento organizado, sobretudo, pela Federação das Sociedades de Assistência aos Lázaros e tratou principalmente de fazer o balanço das políticas de combate à lepra, adotadas por entidades filantrópicas, governos estaduais e Ministério da Educação e Saúde durante a Era Vargas.

\section{Considerações finais}

A Sociedade de Assistência aos Lázaros e Defesa Contra a Lepra foi fundada em 1926, no estado de São Paulo e pouco a pouco adquiriu amplitude nacional, com a criação de entidades congêneres em outras cidades e estados. Embora a filantropia sempre estivesse ligada à assistência social às vítimas do mal de Hansen, a ação dessas entidades foi um marco nas relações com a classe médica e, sobretudo, na relação - nem sempre harmoniosa - com os poderes públicos. Em 1932 foi criada a Federação das Sociedades de Assistência 
aos Lázaros e Defesa Contra a Lepra, com sede na cidade de São Paulo, com o intuito de sistematizar a campanha e articular melhor as filiadas. Enquanto Alice Tibiriçá presidiu a Federação, ela manteve autonomia decisória, o que resultou em constantes choques com as diretrizes da saúde pública paulista.

O ano de 1935 foi decisivo para a Federação, pois a transferência de sua sede para a capital federal coincidiu com a saída de Tibiriçá da presidência da entidade. Eleita então presidente, Eunice Weaver mudou a conduta da Federação, estabelecendo relações mais próximas com o Ministério da Educação e Saúde Pública (1934-1945). A partir de 1935, a adoção, pelo Ministério, do Plano de Combate à Lepra definiu como meta a construção do aparelhamento antileproso em escala nacional. Preventórios administrados pela Federação fariam parte desse aparato oficial, juntamente com dispensários e leprosários. Percebese então o crescimento da campanha preventorial, em grande parte motivado pelo apoio federal. Em 1935, apenas dois estados possuíam preventórios, e outros três tinham pequenos abrigos de emergência; dez anos depois, todas as unidades da federação tinham sido providas de preventórios, e as Sociedades de Assistência aos Lázaros estavam presentes em todo o país. Em discursos e correspondências, o ministro Capanema afirmou que o auxílio dado pela Federação das Sociedades de Assistência aos Lázaros e Defesa Contra a Lepra era basilar para a política do governo federal.

A política preventorial de assistência, desenvolvida pela Federação em parceria com o Ministério da Educação e Saúde, alcançou notoriedade internacional. Além da presidente da Federação das Sociedades de Assistência aos Lázaros e Defesa Contra a Lepra ter visitado vários países para divulgar a política médica e assistencial do ministério varguista, a obra preventorial recebeu elogios na Conferência Pan-americana de Lepra (Rio de Janeiro, 1946), e na Conferência Internacional de Lepra (Havana, 1948) aprovou-se a proposta de assistência social às vitimas do mal de Hansen apresentada por Eunice Weaver.

\section{NOTAS}

* Este artigo se baseia em minha dissertação de mestrado, apresentada ao Programa de Pós-graduação em História das Ciências e da Saúde da Casa de Oswaldo Cruz/Fiocruz (Santos, 2006).

${ }^{1}$ Ver, a respeito, Curi, 2002, Robertson, 2003, Benchimol, Sá, 2004, Cunha, 2005 e Braga, 2006.

${ }^{2}$ A criação de centros de pesquisa - institutos Bacteriológico (1892), Butantã (1901) e Soroterápico Federal (1900) - contribuiu para esse processo em andamento desde o século XIX (Benchimol, Teixeira, 1994).

${ }^{3}$ A capital paulista tinha o Hospital da Luz, fundado no primeiro quartel do século XIX. Por estar localizado muito próximo do bairro da Luz, em crescente expansão, foi fechado em 1904. Nesse mesmo ano inaugurou-se o Hospital do Guapira, no bairro de Jaçanã (Monteiro,1995, p.85-90).

${ }^{4}$ Esse acordo desagradou a direção da Associação Protetora dos Morféticos, pois foi interpretado como intervenção no projeto de sua iniciativa. As discussões entre seus membros levaram à dissolução da entidade em 15 de abril de 1919 (Monteiro, 1995, p.102).

${ }^{5}$ Ver, a respeito, Hochman, 1993, 1998.

${ }^{6}$ Além da presidente e da sua vice, foram eleitas para a diretoria a professora Noemy Silveira (Secretaria) e Felicidade Perpétua de Macedo (Tesouraria) (Documentos..., 1932).

${ }^{7}$ Durante a gestão de Gustavo Capanema, o Ministério passou por uma reforma, em sintonia com a política centralizadora e intervencionista federal. Fonseca $(1993$, p.9) assinala uma de suas principais características: "autoritarismo corporativista, com amplo aparato burocrático-estatal, centralizando as instâncias decisórias superiores e atribuindo ao Executivo autonomia nas decisões finais". Não obstante 
o empenho em atender aos interesses de determinados setores, como forma de legitimar seu poder, o governo federal transformou problemas sociais em alvos de políticas públicas importantes.

${ }^{8}$ Criada em 19 de julho de 1925, a Inspetoria de Profilaxia da Lepra passou a denominar-se Departamento de Profilaxia da Lepra dez anos depois. Ambos foram subordinados à Secretaria Estadual de Educação e Saúde Pública, criada em 3 de março de 1931.

${ }^{9}$ Em 1938 Alice Tibiriçá criou, no Rio de Janeiro, a Instituição Carlos Chagas, que dirigiu até sua morte. A entidade dedicava-se à formação de profissionais para atuar nas campanhas médico-sociais e de assistente sociais. A experiência adquirida no combate à lepra foi aplicada em outras campanhas médicosociais. Em 1944 fundou a Federação das Associações de Combate à Tuberculose, a Sociedade de Amparo aos Psicopatas e uma instituição dedicada aos deficientes visuais. Após o final da Segunda Guerra Mundial, já separada do marido, participou das Uniões Femininas Contra a Carestia. Em 1946 dirigiu o Instituto Feminino de Serviço Construtivo. Em março do ano seguinte apoiou a primeira comemoração do Dia Internacional da Mulher no Brasil. Ainda em 1947, foi indicada como representante do Brasil no Conselho da Federação Democrática Internacional de Mulheres, que ocorreu em Praga, Tchecoslováquia. Dois anos depois, foi eleita primeira presidente da Federação de Mulheres do Brasil, entidade criada após o Congresso das Associações Femininas Estaduais. No final da década de 1940 também participou da campanha O Petróleo é Nosso. Por ocasião de seu falecimento, em junho de 1950, inúmeras homenagens lhe foram prestadas, entre elas a da Associação Brasileira de Leprologia, que considerou seu trabalho o marco inicial da moderna campanha sanitária contra a hanseníase no Brasil (Mott, 2003); o discurso de Souza Araújo na Academia Nacional de Medicina, em que o leprologista ressaltou a importância de Tibiriçá como a "pioneira da profilaxia da lepra no Brasil e, sobretudo, da assistência social à família do leproso" (Sociedades..., 1960, p.18); e elogiosa notícia fúnebre feita por Austregésilo de Athayde e publicada no Diário da Noite (Sociedades..., 1960, p.20).

${ }^{10}$ América Xavier da Silveira provinha de uma família tradicional do Rio de Janeiro.

${ }^{11}$ Ernani Agrícola (1883-1978) formou-se em odontologia em 1912 e sete anos depois diplomou-se médico pela Faculdade de Medicina de Belo Horizonte. Atuou no combate à malária, peste, tuberculose e, especialmente, lepra. Elaborou códigos sanitários e o Plano Nacional de Combate à Lepra em 1935. Participou das comissões responsáveis pelo Plano de Saneamento da Amazônia e por regulamentos para saúde pública federal. Era membro de várias sociedades científicas nacionais e internacionais. Na Era Vargas, teve importante atuação nos órgãos de combate à lepra (Prefeitura... 1979).

${ }^{12}$ Heraclídes César Souza Araújo era um importante leprologista, considerado uma das maiores autoridades no assunto; Ferreira e Souza Campos eram funcionários do Ministério da Educação e Saúde; Eunice Weaver presidia a Federação.

${ }^{13}$ Refiro-me à Campanha Financeira de Béatrix Reynal Para a Sociedade de Lázaros Marina Dias (Campanha..., 1946). Cabe ressaltar que essa Sociedade, localizada no Distrito Federal, foi considerada de utilidade pública pelo decreto municipal 6.756, de 16 de agosto de 1940, e pelo decreto federal 6.527, de 19 de novembro de 1940 (Documentos..., 1939-1940).

${ }^{14}$ Em 15 de maio de 1946, encerrada a campanha de 1943-1945, foram doados Cr $\$ 4.000,00$ aos internos do Hospital Colônia de Curupaiti e Cr\$2.000,00 para os filhos sadios dos lázaros amparados pela Sociedade. Outras doações foram realizadas posteriormente. (Campanha..., 1946). Observe-se que o salário mínimo, em maio de 1943, era Cr\$380,00, valor que se manteve até o final da Era Vargas (Instituto..., 1946).

${ }^{15}$ Em fevereiro de 1946, Maria Capanema compareceu ao almoço oferecido a Eunice Weaver por ocasião do seu afastamento da presidência da Federação. No final daquele mês, Eunice Weaver telegrafou a Capanema desejando boa viagem para os EUA, e mais uma vez destacou seu engajamento na luta contra a lepra (Weaver, 1946). Em 1951, Capanema salientou que todas as homenagens recebidas pela Federação das Sociedades de Assistência aos Lázaros e Defesa Contra a Lepra eram mais que merecidas, pois a força e o engajamento de Eunice Weaver em prol da questão da lepra eram notórias (Weaver, 1951).

${ }^{16} \mathrm{O}$ evento foi organizado pela Federação das Sociedades de Assistência aos Lázaros e Defesa Contra a Lepra, para avaliar e discutir ações políticas no combate à lepra (Conferência..., 1946). 


\section{REFERÊNCIAS}

A ENDEMIA...

A endemia leprótica no Estado de São Paulo: recursos financeiros e suas aplicações. São Paulo. Arquivo Gustavo Capanema; série Correspondência; GC h 1935.09.02 (Centro de Pesquisa e Documentação de História Contemporânea do Brasil). 1939.

ABREU, Alzira Alves et al. (Coord.). Dicionário histórico biográfico brasileiro - pós 1930. 2.ed. Rio de Janeiro: Fundação Getúlio Vargas. 2001.

ARAÚJO, Heraclídes César de Souza. História da lepra no Brasil: período republicano (1890-1952). Rio de Janeiro: Imprensa Nacional. 1956.

AS GRANDES OBRAS...

As grandes obras de benemerência: um belo movimento em prol dos lázaros e contra a lepra. Correio Paulistano, São Paulo, p.4. 30 abr. 1926.

BENCHIMOL, Jaime Larry et al.

Cerejeiras e cafezais: as relações médicocientíficas entre Brasil e Japão e a saga de Hideyo Noguchi. Rio de Janeiro: Bom Texto. 2009.

BENCHIMOL, Jaime Larry; SÁ, Magali Romero (Org.).

Adolpho Lutz: obra completa. Hanseníase. Rio de Janeiro: Fiocruz. v.1, livro 2. 2004.

BENCHIMOL, Jaime Larry; TEIXEIRA, Luis Antonio.

Cobras e lagartos \& outros bichos: uma história comparativa dos institutos Butantã e Oswaldo Cruz. Rio de Janeiro: Fundação Oswaldo Cruz. 1994.

BRAGA, Andrea Baptista.

'O que tem que ser tem força': narrativa sobre a doença e a internação de Pedro Baptista, leproso, meu avô (1933-1955). Dissertação (Mestrado) - Programa de Pós-graduação em História das Ciências e da Saúde, Casa de Oswaldo Cruz, Fiocruz, Rio de Janeiro. 2006.

CAIUBY, Adelardo Soares.

Projeto da leprosaria modelo nos campos de Santo Ângelo, Estado de São Paulo. São Paulo: Riedel. 1918.

CAIXA BENEFICENTE..

[Documento referentes à Caixa Beneficente do asilo-colônia Pirapitingui]. Arquivo Gustavo Capanema; série Correspondência; GC h 1935.09.02 (Centro de Pesquisa e Documentação de História Contemporânea do Brasil). 1939.
CAMPANHA...

Campanha Financeira de Béatrix Reynal para a Sociedade de Lázaros Marina Dias; Biblioteca Nacional, setor Manuscritos; 24,3,5 - n.3 (Biblioteca Nacional). 1946.

CAPANEMA, Gustavo.

Ampliando o nosso aparelhamento antileproso. Rio de Janeiro. Arquivo Gustavo Capanema; GC h 1935.09.02. datil. (Centro de Pesquisa e Documentação de História Contemporânea do Brasil). 1937.

CONFERÊNCIA...

Conferência de Assistência Social aos Lázaros, 2., jul. 1945, Rio de Janeiro. Anais..., Rio de Janeiro: Federação das Sociedades de Assistência aos Lázaros e Defesa Contra a Lepra. v.3. 1946.

CUNHA, Vivian da Silva.

O isolamento compulsório em questão: políticas de combate à lepra no Brasil (1920-1941).

Dissertação (Mestrado) - Programa de Pósgraduação em História das Ciências e da Saúde, Casa de Oswaldo Cruz, Fiocruz, Rio de Janeiro. 2005.

CURI, Luciano M.

Defender os sãos e consolar os lázaros: lepra e isolamento no Brasil, 1935/1976. Dissertação (Mestrado) - Universidade Federal de Uberlândia, Uberlândia. 2002.

\section{DOCUMENTOS...}

[Documentos referentes à criação da Federação das Sociedades de Assistência aos Lázaros e Defesa Contra a Lepra]. Arquivo Gustavo Capanema; série Correspondência; GC h 1935.09.02 (Centro de Pesquisa e Documentação de História Contemporânea do Brasil). 1932.

\section{DOCUMENTOS...}

[Documentos referentes à construção de um preventório em Vitória]. Arquivo Gustavo Capanema; série Correspondência; GC h 1935.09.02 (Centro de Pesquisa e

Documentação de História Contemporânea do Brasil). 1938-1940.

\section{DOCUMENTOS...}

[Documentos referentes à Federação das Sociedades de Assistência aos Lázaros e Defesa Contra a Lepra]. Arquivo Gustavo Capanema; série Correspondência; GC h 1935.09.02 (Centro de Pesquisa e Documentação de História Contemporânea do Brasil). 1935.

DOCUMENTOS...

[Documentos referentes à Sociedade

Amazonense de Assistência aos Lázaros e Defesa 
Contra a Lepra]. Arquivo Gustavo Capanema; série Correspondência; GC h 1935.09.02 (Centro de Pesquisa e Documentação de História Contemporânea do Brasil). 1940.

DOCUMENTOS...

[Documentos referentes à Sociedade de Assistência aos Lázaros e Defesa Contra a Lepra do Distrito Federal]. Arquivo Gustavo Capanema; série Correspondência; GC h 1935.09.02 (Centro de Pesquisa e

Documentação de História Contemporânea do Brasil). 1939-1940.

EXTRATO DOS ESTATUTOS...

Extrato dos estatutos da Caixa Beneficente do Asilo-Colônia Pirapitingui. Arquivo Gustavo Capanema; série Correspondência; GC h 1935.09.02 (Centro de Pesquisa e

Documentação de História Contemporânea do Brasil). 1939.

FEDERAÇÃO...

Federação das Sociedades de Assistência aos Lázaros e Defesa Contra a Lepra. Uma campanha de solidariedade humana e interesse nacional. Rio de Janeiro: Federação das Sociedades de Assistência aos Lázaros e Defesa Contra a Lepra. 1943.

FONSECA, Cristina Maria Oliveira. Saúde no Governo Vargas (1930-45): dualidade institucional de um bem público. Rio de Janeiro: Editora Fiocruz. 2007.

FONSECA, Cristina Maria Oliveira. Ideologia e políticas públicas: a construção da nação e a reforma do Ministério da Educação e Saúde Pública (1934-1937). Trabalho apresentado no Seminário Interno do Departamento de Pesquisa da Casa de Oswaldo Cruz, 3., Fiocruz, Rio de Janeiro. 1993.

HOCHMAN, Gilberto.

A era do saneamento: as bases da política da saúde pública no Brasil. São Paulo: Hucitec; Anpocs, 1998.

HOCHMAN, Gilberto.

Regulando os efeitos da interdependência: sobre as relações entre saúde pública e construção do Estado (Brasil, 1910-1930). Estudos Históricos, Rio de Janeiro, v.6, n.11, p.40-61. 1993.

\section{INSTITUTO...}

Instituto Brasileiro de Geografia e Estatística (IBGE). Anuário Estatístico do Brasil. Rio de Janeiro: IBGE. Disponível em: http:// memoria.nemesis.org.br/pub/90000/ 90000009r.pdf. Acesso em: 28 out. 2011. 1946.

MEMORIAL..

[Memorial da Federação das Sociedades de Assistência aos Lázaros e Defesa Contra a
Lepra]. Arquivo Gustavo Capanema; série Correspondência; GC h 1935.09.02 (Centro de Pesquisa e Documentação de História Contemporânea do Brasil). 1938.

MIRANDA, Maria Augusta Tibiriçá.

Alice Tibiriçá, lutas e ideais. Rio de Janeiro: PLG. 1981.

MONTEIRO, Yara Nogueira.

Da maldição divina à exclusão social: um estudo da hanseníase em São Paulo. Tese (Doutorado) - Faculdade de Filosofia, Letras e Ciências Humanas, Universidade de São Paulo, São Paulo. 1995.

MOTT, Maria Lucia.

Trabalhando para a formação um mundo melhor: as lutas e as ideias de Alice Tibiriçá. Trabalho apresentado no Encontro Regional de História Democracia e Conflito, Universidade do Estado do Rio de Janeiro, 11., Rio de Janeiro. 2003.

MOURA, Gerson.

Neutralidade dependente: o caso do Brasil, 1939-42. Estudos Históricos, Rio de Janeiro, v.6, n.12, p.177-189. 1993.

PREFEITURA...

Prefeitura da Cidade do Rio de Janeiro. Secretaria Municipal de Saúde. Departamento Geral de Saúde Pública (DGSP). I Região Administrativa. Centro Municipal de Saúde Ernani Agricola. Rio de Janeiro: DGSP. Disponível em:

http://www.saude.rio.rj.gov.br/servidor/cgi/ public/cgilua.exe/web/templates/htm. Acesso em: 23 jun. 2006. 1979.

REGULAMENTO...

Regulamento dos preventórios para filhos sadios de lázaros instalados no Brasil. Arquivo Gustavo Capanema; série Correspondência; GC h 1935.09.02 (Centro de Pesquisa e

Documentação de História Contemporânea do Brasil). 1940.

ROBERTSON, Jo (Ed.).

Leprosy: a long history of stigma. História, Ciências, Saúde - Manguinhos, Rio de Janeiro, v.10, supl. 1. 2003.

SANGLARD, Gisele P.

Entre os salões e o laboratório: filantropia, mecenato e práticas científicas, Rio de Janeiro, 1920-1940. Tese (Doutorado) - Programa de Pós-graduação em História das Ciências e da Saúde, Casa de Oswaldo Cruz, Fiocruz, Rio de Janeiro. 2005.

SANTOS, Vicente Saul Moreira dos. Entidades filantrópicas \& políticas públicas no combate à lepra: Ministério Gustavo Capanema (1934-1945). Dissertação (Mestrado) - 
Programa de Pós-graduação em História das Ciências e da Saúde, Casa de Oswaldo Cruz, Fundação Oswaldo Cruz, Rio de Janeiro. 2006.

SCHUMAHER, Schuma; BRAZIL, Érico Vital (Org.).

Dicionário mulheres do Brasil: de 1500 até a atualidade. Rio de Janeiro: Jorge Zahar. 2000.

SOCIEDADE DO DISTRITO FEDERAL...

Sociedade do Distrito Federal de Assistência aos Lázaros. O Jornal, Rio de Janeiro, 14 abr. 1945.

SOCIEDADES...

Sociedades de Assistência aos Lázaros e Defesa Contra a Lepra. Alice Tibiriçá: traços biográficos. São Paulo: Sociedades de Assistência aos Lázaros e Defesa Contra a Lepra. 1960.

TORRES, Diana Obregon.

Batallas contra la lepra: Estado, medicina y ciencia en Colombia. Medellín: Banco de la República; Fondo Editorial Universidad Eafit. 2002.

VARGAS, ALZIRA.

[Carta de Alzira Vargas para Gustavo Capanema encaminhando pedido do governo cubano de todas as publicações do ministério sobre a lepra]. Arquivo Gustavo Capanema; série Correspondência; GC h 1935.09.02 (Centro de Pesquisa e Documentação de História Contemporânea do Brasil). 1939.
WEAVER, Eunice

[Documentos sobre a trajetória de Eunice Weaver na Federação das Sociedades de Assistência aos Lázaros e Defesa Contra a Lepra]. Rio de Janeiro. Arquivo Gustavo Capanema; série Correspondência; GC b Weaver E CPDOC/FGV. (Centro de Pesquisa e Documentação de História Contemporânea do Brasil). 1951.

\section{WEAVER, Eunice.}

Os preventórios do Brasil no momento: a razão dos preventórios. Rio de Janeiro. Arquivo Gustavo Capanema; série Correspondência; GC pi Weaver E. 1949.00.00 (Centro de Pesquisa e Documentação de História Contemporânea do Brasil). 1949.

WEAVER, Eunice.

[Documentos sobre a trajetória de Eunice Weaver na Federação das Sociedades de Assistência aos Lázaros e Defesa Contra a Lepra]. Rio de Janeiro. Arquivo Gustavo Capanema; série Correspondência; GC b Weaver E CPDOC/FGV. (Centro de Pesquisa e Documentação de História Contemporânea do Brasil). 1946.

WEAVER, Eunice.

[Carta ao presidente Vargas, sobre decisões tomadas na Conferência Nacional de Assistência Social aos Lázaros em novembro de 1939]. Arquivo Gustavo Capanema; série Correspondência; GC h 1935.09.02 (Centro de Pesquisa e Documentação de História Contemporânea do Brasil). 1939. 